\title{
Stepper Motor Device
}

National Cancer Institute

\section{Source}

National Cancer Institute. Stepper Motor Device. NCI Thesaurus. Code C50078.

A motor designed to rotate in fixed increments. 